\title{
Research
}

\section{Is healthy eating for obese children necessarily more costly for families?}

\begin{abstract}
\section{Background}

During consultations on weight management in childhood obesity clinics, the additional costs incurred by healthy eating are often cited, as an economic barrier to achieving a better nutritional balance.
\end{abstract}

\section{Aim}

To examine whether adopting an improved theoretical, balanced diet compared to current dietary habits in children incurs additional cost

\section{Design and setting}

Children aged $5-16$ years (body mass index [BMI] $\geq 98$ th percentile) recruited to a randomised trial comparing a hospital-based and primary care childhood obesity clinics provided data for this study.

\section{Method}

Three-day dietary diaries collected at baseline were analysed for energy and fat intake and then compared to a theoretical, adjusted healthyeating diet based on the Food Standards Agency, 'Eatwell plate'. Both were priced

contemporaneously using the appropriate portion size, at a neighbourhood, mid-range supermarket, at a budget supermarket, and on the local high street.

\section{Results}

The existing diet purchased at a budget supermarket was cheapest (£2.48/day). The healthier, alternative menu at the same shop cost an additional 33 pence/day (£2.81). The same exercise in a mid-range supermarket, incurred an additional cost of 4 pence per day ( $€ 3.40$ versus $\mathrm{E} 3.44$ ). Switching from an unhealthy midrange supermarket menu to the healthier, budget-outlet alternative saved 59 pence per day. The healthier, alternative menu was cheaper than the existing diet if purchased on the high street ( $€ 3.58$ versus $€ 3.75$ ), although for both menus this was most expensive.

\section{Conclusion}

For many obese children, eating healthily would not necessarily incur prohibitive, additional financial cost, although a poor diet at a budget supermarket remains the cheapest of all options. Cost is a possible barrier to healthy eating for the most economically disadvantaged.

\section{Keywords}

child health; child overnutrition; food cost; obesity; primary care.

\section{INTRODUCTION}

One of the cornerstones of weight management in obese children is nutritional advice aimed at improving the level of healthy eating, based on the Food Standards Agency's 'Balance of Good Health, Eat Well Plate' directive." However, a significant barrier to achieving healthier eating behaviours, which the authors have encountered in the clinic, is the perception of both parents and some health professionals that healthy eating is, by necessity, more expensive. ${ }^{2}$ To some extent, this perception is supported by studies examining differential food costs in both the $\mathrm{UK}^{3}$ and US. ${ }^{4}$ While conducting a study examining the feasibility of moving a hospital-based weight-management programme for children into primary care, the authors used data from food diaries of obese children with a body mass index (BMI) greater than the 98th percentile, to test the hypothesis that developing a model diet plan aimed at altering eating habits to improve healthy food choices as a component of a weightmanagement programme would entail excess cost to families. ${ }^{5}$ These families might already be suffering from significant economic constraints, as obesity is possibly, although not necessarily, more prevalent among those in the lower socioeconomic groupings. ${ }^{6-8}$

J Banks, PhD, research programme manager; DJ Sharp, MD, MRCP. FRCPCH, professor of primary health care, Academic Unit of Primary Health Care, School of Social and Community Medicine, University of Bristol, Bristol. J Williams, BSc, SRD, early years healthy weight manager, Directorate of Public Health, NHS Bristol, Bristol. T Cumberlidge, DipCNM MBANT, dietetic assistant, Home Management Services, Bristol Royal Infirmary, Bristol. T Cimonetti, dietitian, Department of Nutrition and Dietetics, Bristol Royal Hospital for Children, University Hospitals Bristol NHS Foundation Trust, Bristol. JPH Shield, MD, professor of diabetes and metabolic endocrinology. School of Clinical Sciences, University of Bristol and Bristol

\section{METHOD}

Children aged $5-16$ years, with a BMI $\geq 98$ th percentile, were recruited to the trial between April 2008 and June 2009, having been referred from primary care for weight management. After being screened for comorbidities and indicating their consent to be included in the trial, families were randomised to either a hospital-based clinic or primary care clinics situated in a large general practice to the north of Bristol or a health park in the south of the city. Prior to baseline, families were requested to fill in a 3-day dietary diary as accurately as possible, to bring to their first clinic appointment. The diaries were then scored for frequency of foods from each of the five food groups, and a calorific value was obtained using a food intake plan tool. ${ }^{9}$ From the diaries completed, 13 were considered comprehensive in tabulation of food eaten over the 3 days, and were used in this study.

The selected diaries were analysed by obtaining weights for the foods consumed using the Food Portion Sizes Book. ${ }^{10}$ Then, using McCance and Widdowson's Food table, ${ }^{11}$ a value was obtain for energy (calories) and fat intake.

The diary food information data were then theoretically adjusted to meet the estimated average requirements (EARs) for each participant, and current healthy eating

Royal Hospital for Children, Bristol.

\section{Address for correspondence}

Professor Julian Shield, Department of Paediatric Endocrinology, Bristol Royal Hospital for Children, Upper Maudlin Street, Bristol, BS2 8AE.

E-mail: j.p.h.shieldabristol.ac.uk

Submitted: 12 April 2011; Editor's response: 19 July 2011; final acceptance:

9 September 2011

\section{CBritish Journal of General Practice}

This is the full-length article (published online 27 Dec 2011) of an abridged version published in print. Cite this article as: Br J Gen Pract 2012 DOI: 10.3399/bjgp12X616300 


\section{How this fits in}

In primary and secondary care consultations addressing lifestyle changes to improve weight, health professionals frequently believe, and patients often cite, the extra economic burden of eating more healthily as a barrier to improved dietary habits. This study demonstrates that adopting a healthier diet is not necessarily economically prohibitive and patients should be encouraged to 'shop around' to reduce food bills when making these changes. A caveat to this message is that it is likely that the most economically disadvantaged, who may already purchase all food at budget supermarkets, will necessarily pay more to eat healthily.

guidelines promoted by the 'Eatwell plate'. Each of the adjusted daily diets met EAR, included at least three meals, and snacks were allowed (Table 1). The menus also ensured that the daily intake included three portions of dairy produce, protein (meat, fish, eggs, or vegetarian alternative) in at least two meals, carbohydrate with each meal, and five portions of fruit and vegetables throughout the day. Daily intake in this adjusted menu allowed one or two 'treats' such as biscuits or ice cream Irepresented on the 'Eatwell plate' as the fats and sugars section).
The menus (existing and adjusted) were then priced by obtaining the cost per 100 grams and calculating the cost of the relevant portion size for the child. Each item of food was priced for comparison at a major UK mid-range supermarket, a budget supermarket, and in local shops on a high street, all located within walking distance of the obesity clinic at the general practice in the north of the city. The costing of both menus was undertaken at each retail outlet in the same week (mid July 2010). Where direct comparisons were not available, for example when the budget supermarket did not stock a particular brand, a closely related product was used (for instance, satsumas for oranges, shortcake biscuits for all-butter biscuits).

\section{RESULTS}

The 13 diaries identified for this study were collected from 2 boys and 11 girls, with a mean age of 9.2 years (range 5.7-13.6 years) and BMI standard deviation score (SDS) of 3.0 (median 2.9, range 2.1-4.7).

Baseline measures indicated that the mean excess calorie intake per day for the group compared to the EAR was 221 calories. The adapted 'healthy' diet produced a mean calorie intake that was very close (7 calories) to the recommended EAR (Table 2).

\section{Table 1. Examples of substitutions made from existing diet to healthy alternative with estimations of change in kilocalories and fat consumption if adhered to}

\begin{tabular}{|c|c|c|c|c|}
\hline & Existing diet & Alternative healthy option & Kcal change & Grams \\
\hline & 2 slices of white toast with margarine & 2 slices of white toast with LF spread & -59.2 & -6.9 \\
\hline & Cereal in whole milk & Cereal in SS milk & -20 & -2.2 \\
\hline$\frac{\substack{\pi \\
\frac{\pi}{\pi} \\
\frac{\pi}{\pi}}}{2}$ & 2 slices of white toast with paté + crisps + cola & $\begin{array}{l}2 \text { slices of white toast with LF butter + apple } \\
+ \text { glass SS milk }\end{array}$ & -257.8 & -14.7 \\
\hline $\bar{\oplus}$ & Large portion of Honeynut Cheerios ${ }^{\circledR}+$ glass of SS milk & 1 portion of Cheerios $^{\circledR}+$ banana & -127.3 & -6.2 \\
\hline & Chocolate spread (on toast) & LF butter on toast & -104 & -4 \\
\hline $\mathcal{气}$ & Crisps +3 slices of white bread with butter & $\begin{array}{l}4 \text { slices of white bread with roast chicken, LF butter } \\
\text { and mixed salad }\end{array}$ & -103.3 & -22.4 \\
\hline 气 & 1 portion fried chicken & Roast chicken & -141 & -8.4 \\
\hline & 2 rashers of bacon +2 thin sausages + finger roll & 2 thin sausages +2 slices of bread $+L F$ butter & -58 & -5 \\
\hline & 1 pack ready made lasagne & $1 / 2$ pack of lasagne + carrots + apple & -193 & -13.1 \\
\hline & 3 roast potatoes & 2 roast potatoes +2 slices of roast chicken & -5 & -1 \\
\hline 竞 & 3 slices of pizza & $\begin{array}{l}2 \text { slices of vegetable pizza }+ \text { mixed salad }+ \\
\text { glass of orange juice }\end{array}$ & -253.4 & -8.5 \\
\hline & 1 slice of gammon & 1 portion of roast pork & -150.7 & -6.7 \\
\hline$\stackrel{n}{c}$ & Cola & Zero cola & -82 & 0 \\
\hline & 1 mini pack of Jelly Tots ${ }^{\circledR}$ & 1 tbsp mixed nuts & -25 & +10.8 \\
\hline & 1 slice of cheesecake + cream & 1 fruit ice pop & -297.7 & -20 \\
\hline 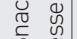 & 1 pack of Rolos ${ }^{\circledR}$ & 3 sweet biscuits & -130 & -7.2 \\
\hline & 2 chocolate biscuits & 4 rice cakes & -77.7 & -7.7 \\
\hline & 1 pack of Haribo ${ }^{\circledR}$ Jellies & 1 portion of rice pudding with SS milk & -251 & +0.2 \\
\hline
\end{tabular}




\section{Table 2. Demonstrating documented calorie intake from food diaries and the results of healthy-eating substitutions on projected calorie intake}

\begin{tabular}{lccccc} 
ID & $\begin{array}{c}\text { EAR } \\
\text { (calories) }\end{array}$ & $\begin{array}{c}\text { Calories of } \\
\text { existing diaries }\end{array}$ & $\begin{array}{c}\text { Calories of } \\
\text { adapted healthy diaries }\end{array}$ & $\begin{array}{c}\text { Excess calories } \\
\text { of existing diary }\end{array}$ & $\begin{array}{c}\text { Excess calories } \\
\text { of healthy diary }\end{array}$ \\
\hline 13 & 1740 & 1530 & 1747 & -210 & 7 \\
\hline 22 & 1845 & 1617 & 1896 & -228 & 51 \\
\hline 34 & 1740 & 1645 & 1690 & -95 & -50 \\
\hline 38 & 1740 & 2002 & 1745 & 262 & 5 \\
\hline 100 & 1715 & 1860 & 1682 & 145 & -33 \\
\hline 102 & 1740 & 2634 & 1715 & 894 & -25 \\
\hline 105 & 2220 & 2990 & 2212 & 770 & -8 \\
\hline 111 & 1845 & 2385 & 1806 & 540 & -39 \\
\hline 112 & 1740 & 2075 & 1828 & 335 & 88 \\
\hline 117 & 1545 & 1713 & 1577 & 168 & 32 \\
\hline 121 & 1740 & 2045 & 1699 & 305 & -41 \\
\hline 147 & 1845 & 2226 & 1904 & 381 & 59 \\
\hline 152 & 1740 & 1348 & 1786 & -392 & 46 \\
\hline Mean & & & 221 & 7 &
\end{tabular}

$E A R=$ estimated average requirement.

Table 3. Relative costs ( $\mathrm{\epsilon}$ ) of existing diets compared to an adapted healthy diet $(n=13)$

\begin{tabular}{lccc} 
& $\begin{array}{c}\text { Existing diaries } \\
\text { (mean = 221 calories } \\
\text { over EAR) }\end{array}$ & $\begin{array}{c}\text { Adapted diaries } \\
\text { (mean = 7 calories } \\
\text { over EAR) }\end{array}$ & $\begin{array}{c}\text { Mean price difference } \\
\text { (adapted } \\
\text { minus existing) }\end{array}$ \\
\hline Supermarket & 3.40 & 3.44 & 0.04 (per week 0.28) \\
\hline Budget supermarket & 2.48 & 2.81 & 0.33 (per week 2.31) \\
\hline Independent shops & 3.75 & 3.58 & -0.17 (per week -1.19) \\
\hline
\end{tabular}

In terms of daily cost, the cheapest option at $€ 2.48$ per day was the existing diet purchased at a budget supermarket. Adapting this diet to healthier options at the same centre of purchase resulted in a increase in daily cost of 33 pence to $€ 2.81$. In the case of a mid-range supermarket, adapting the existing diary to healthier options resulted in a negligible increase in cost of 4 pence per day, from $€ 3.40$ to $€ 3.44$, while adapting high street, independent shopping actually resulted in a 17 pence per day (£3.58 compared to £3.75) lower cost for a healthier diet (Table 3).

Given that some dietary diaries indicated a calorie deficit compared to EAR, which seemed unlikely to be accurate in those attending an obesity clinic at least in the long-term, the study also analysed the changes in cost for only those with a positive calorie balance above EAR on the 3-day diaries $(n=9)$. All costs rose in this example, and the comparisons between shop types changed slightly - the gap between the existing and healthy diet reduced to 23 pence per day for the budget supermarket, while the healthier option proved less expensive for the mid-range supermarket and independent high street shops (Table 4).

\section{DISCUSSION}

\section{Summary}

The study sought to examine the hypothesis that a real barrier to healthier eating in families with obese children is the added expense of such a lifestyle modification. While in absolute terms the cheapest option was to purchase foods of low nutritional quality from a budget supermarket, it was possible to identify healthier alternatives for an extra £2.31 per week in the same store. However, it was possible to eat a healthy diet for virtually the same cost at a midrange supermarket la negligible 28 pence per week extra). Those people with no local supermarket appear to be able to reduce costs by switching to healthier options if all that is available is a local high street with independent traders. Furthermore, the study demonstrates that it is entirely possible to switch from eating a diet of low nutritional quality from a mid-range supermarket to a healthy diet from a budget supermarket and still reduce food costs. The conclusions are similar when analysing all baseline diaries, whether they reported sufficient food intake to attain daily EAR or not, or when only using those in which EAR was in a neutral or positive balance - a more likely scenario in a weightmanagement clinic.

\section{Strengths and limitations}

There are caveats to this work. The cost analysis of a healthy diet was based on models of better practice rather than actual changes in eating behaviours of these participants. Furthermore, it is undoubtedly the case that other factors such as taste, ${ }^{12}$ time scarcity, ${ }^{13}$ and cooking skills of the family ${ }^{14}$ impact upon family food-purchasing choices. Finally, in the present economic climate, it is possible that the current cost of healthier food might rise at a higher trajectory than for low-cost, energy-dense food types. However, food cost is frequently cited as a reason for failure to address eating behaviours in the authors' clinical practice with obese children, and the study demonstrates that, at the moment, for the majority, this is a perceived rather than real barrier to making the necessary dietary changes.

\section{Comparison with existing literature}

The lowest decile of income before housing costs of low-income families for homeowners is $€ 231$, while that for tenants is $€ 163 .{ }^{15}$ In these very low-income families, incurring an extra $€ 2.31$ per week in food costs may well preclude switching to healthier alternatives. For such families, 


\begin{tabular}{|c|c|c|c|}
\hline & $\begin{array}{c}\text { Existing diaries } \\
\text { (mean }=441 \\
\text { calories over EAR) }\end{array}$ & $\begin{array}{l}\text { Adapted diaries } \\
\text { (mean = } 3 \\
\text { calories over EAR) }\end{array}$ & $\begin{array}{c}\text { Mean price difference } \\
\text { (adapted } \\
\text { minus existing) }\end{array}$ \\
\hline Supermarket & 3.58 & 3.53 & -0.05 (per week -0.35) \\
\hline Budget supermarket & 2.71 & 2.95 & 0.23 (per week 1.61) \\
\hline Independent shops & 4.04 & 3.73 & -0.30 (per week -2.10) \\
\hline
\end{tabular}

cost will be a factor and there may be a case for a voucher distribution through the benefit system or a discount card that specifically could be redeemed for healthy foods in participating shops. ${ }^{16}$ Currently, 'Healthy Start' vouchers offer eligible families of children under 4 years of age, £3.20 per week: the vouchers can be used to purchase milk, fruit, and vegetables. ${ }^{17}$ However, recent data point to socioeconomic status contributing little to this current obesity epidemic, ${ }^{7,818}$ and thus the authors believe that these data indicate that for the majority of families in this country, it is possible to eat more healthily for little to no additional cost, and the perceived cost barrier is not in fact a reality. The present work is borne out by other studies in the US and New Zealand that have demonstrated no extra incurred cost in adopting a healthier diet. 19,20

Implications for research and practice While further research on the real cost implications of healthy eating are warranted, consultations in general practice addressing weight may benefit from actively challenging a universal presumption that healthy eating is necessarily more expensive.

\section{Funding}

This paper presents independent research commissioned by the National Institute for Health Research (NIHR) under its Research for Patient Benefit (RfPB) Programme Reference Number PB-PG-0706-10090. The views expressed are those of the author(s) and not necessarily those of the $\mathrm{NHS}$, the NIHR, or the Department of Health.

\section{Ethics committee}

Ethical approval for the study was granted by Southmead Research Ethics Committee on 18/07/2007. MREC No: 07/Q2002/35.

\section{Provenance}

Freely submitted; externally peer reviewed.

\section{Competing interests}

The author has stated that there are none.

\section{Trial details}

The data were collected as part of a trial entitled 'Evaluating the transferability of a successful, hospital-based, childhood obesity clinic to primary care: a pilot study'. The study was registered at ClinicalTrials.gov NCT00536536.

\section{Discuss this article}

Contribute and read comments about this article on the Discussion Forum: http://www.rcgp.org.uk/bjgp-discuss 


\section{REFERENCES}

1. Food Standards Agency. The eatwell plate.

http://mww.food.gov.uk/northernireland/nutritionni/niyoungpeople/survivorform/b readandbutterstuff/eatwellplate laccessed 26 Sep 2011).

2. Turner KM, Shield JP, Salisbury C. Practitioners' views on managing childhood obesity in primary care: a qualitative study. Br J Gen Pract 2009; 59(568): 856-862.

3. Cade J, Upmeier H, Calvert C, Greenwood D. Costs of a healthy diet: analysis from the UK Women's Cohort Study. Public Health Nutr 1999; 2(4): 505-512.

4. Monsivais P. Drewnowski A. The rising cost of low-energy-density foods. J Am Diet Assoc 2007; 107(12): 2071-2076.

5. Drewnowski A, Darmon N. The economics of obesity: dietary energy density and energy cost. Am J Clin Nutr 2005; 82(1 Suppl): 265S-273S.

6. Brunt H, Lester N, Davies G, Williams R. Childhood overweight and obesity: is the gap closing the wrong way? J Public Health (Oxf) 2008; 30(2): 145-152.

7. Taylor SJ, Viner R, Booy R, et al. Ethnicity, socio-economic status, overweight and underweight in East London adolescents. Ethn Health 2005; 10(2): 113-128.

8. Sweeting $H$, West $P$, Young R. Obesity among Scottish 15 year olds 1987-2006: prevalence and associations with socio-economic status, well-being and worries about weight. BMC Public Health 2008; 8: 404.

9. Hunt P. So you want to lose weight ... for good. A guide to losing weight for men and women. London: British Heart Foundation, 2005.

http://www.bhf.org.uk/plugins/PublicationsSearchResults/DownloadFile.aspx?do cid=e797cf7e-96d2-4b9b-b503-7cd10f5c475f\&version=-

$1 \&$ title=M2L+So+You+Want+To+Lose+Weight...+For+Good+(large+print)\&resourc e=M2L laccessed 30 Nov 2011).
10. Crawley H. Food portion sizes. 2nd edn. London: HMSO, 1990.

11. McCance RA, Widdowson EM. McCance and Widdowson's the composition of foods. 6th summary ed, compiled by Food Standards Agency and Institute of Food Research. Cambridge: Royal Society of Chemistry, 2002.

12. Drewnowski A, Specter SE. Poverty and obesity: the role of energy density and energy costs. Am J Clin Nutr 2004; 79(1): 6-16.

13. Jabs J, Devine CM. Time scarcity and food choices: an overview. Appetite 2006; 47(2): 196-204.

14. Pettinger $C$, Holdsworth $M$, Gerber M. Meal patterns and cooking practices in Southern France and Central England. Public Health Nutr 2006; 9(8): 1020-1026.

15. Meadows P, Rogger D. Low-income homeowners in Britain: descriptive analysis. Department for Work and Pensions, Research Report 251. Norwich: HMSO, 2005

16. Waterlander WE, de Mul A, Schuit AJ, et al. Perceptions on the use of pricing strategies to stimulate healthy eating among residents of deprived neighbourhoods: a focus group study. Int J Behav Nutr Phys Act 2010; 7: 44.

17. Healthy Start. http://www.healthystart.nhs.uk laccessed 26 Sep 2011).

18. Sabin MA, Ford A, Hunt $L$, et al. Which factors are associated with a successful outcome in a weight management programme for obese children? J Eval Clin Pract 2007; 13(3): 364-368.

19. Ni Mhurchu C, Ogra S. The price of healthy eating: cost and nutrient value of selected regular and healthier supermarket foods in New Zealand. N Z Med J 2007; 120(1248): U2388.

20. Raynor HA, Kilanowski CK, Esterlis I, Epstein LH. A cost-analysis of adopting a healthful diet in a family-based obesity treatment program. J Am Diet Assoc 2002; 102(5): 645-656. 